\title{
Exploration of High Risk Pregnancy Early Detection Model for Cadre in the Working Area of Rasimah Ahmad Public Health Center Bukittinggi, West Sumatera Province, Indonesia
}

\author{
Hasrah Murni ${ }^{1}$ \\ ${ }^{1}$ Diploma III of Midwifery, Health Polytechnic, Bukittinggi, Indonesia \\ Correspondence: Hasrah Murni, Diploma III of Midwifery, Padang Health Polytechnic, Jalan Adhiaksa No.1 \\ Bukittinggi, Bukittinggi 26136, Indonesia. Email: hasrahmurni54@gmail.com
}

Received: September 4, 2019 Accepted: May 26, 2020 Online Published: May 31, 2020

doi:10.5539/gjhs.v12n7p155

URL: https://doi.org/10.5539/gjhs.v12n7p155

\begin{abstract}
The decreasing number of MMR and IMR can be achieved if the number of high-risk pregnant women decreases. To anticipate this, an approach should be made through individuals who are closest to the community to provide information about high-risk pregnancies such as health cadres. However, cadres' knowledge and attitudes regarding their roles and duties as assistants for high-risk pregnant women and early detection of high risk are still very low. Therefore, it is necessary to increase the knowledge and attitude of health cadres by using appropriate and effective learning media sources in accordance with their knowledge and needs. The general purpose of this study is to explore and identify the perspectives and experiences of health cadres in providing assistance to high-risk pregnant women. The study uses the qualitative research method. It was conducted in the working area of Rasimah Ahmad Bukittinggi Health Center in July - October 2018. The subjects of this study consisted of health cadres, KIA program designers, and policy makers. The data were collected by using in Depth Interview and Focus Group Discussion. They were analyzed by using interactive analysis method.The result of the study shows that there is still a lack of knowledge of cadres regarding their roles and duties as assistants for high-risk pregnant women and early detection of high risk of pregnancy. This is due to the absence of handbook for cadres in providing information / and counseling to regnant women other than the KIA books they have been using and the experiences they have gained so far. The conclusion of this study is there is lack of learning media sources for cadres in providing services to pregnant women. Hence, the learning media resources are urgently needed as a reference in giving quality assistance.
\end{abstract}

Keywords: pregnancy, high risk, early detection, health cadre

\section{Introduction}

High-risk pregnancy is a pregnancy or a fetus that has a poor outcome if it is carried out using common treatment as in normal cases. The causes of high-risk pregnancies due to women's lack of knowledge about pregnancy, low socio-economic status, education and poor information. High-risk pregnancy on mother is related to the high mortality of mother and baby (Manuaba, 2007) .

According to the data of the World Health Organization (WHO), 830 women died because of complication during pregnancy and childbirth every day in 2015 . The Sustainable Development Goals (SDG's) aim to reduce the number of maternal mortality globally from 216 per 100,000 live births to 70 per 100,000 live births in 2030 (WHO, 2017). Meanwhile the infant mortality rate (IMR) 2015 worldwide ranged around 19 deaths per 1000 live births (World Health Organization, 2015).

Southeast Asia is the second highest rate region after North Africa in terms of maternal and infant mortality. Indonesia is one of the ASEAN countries which has a high number of maternal deaths with 214 per 100,000 live births, Malaysia has 39 per 100,000 live births, Brunei has 60 per 100,000 live births, and Vietnam has 160 per 100,000 live births. (World Health Organization, 2015). Based on the survey conducted by Medical Faculty of Andalas University in 2013, the number of maternal death in West Sumatera was 90 (Health Agency of West Sumatra, 2017).

Several efforts to reduce the MMR and IMR in Indonesia based on the Indonesia health program of the National Medium-Term Development Plan (RPJMN) 2015-2019 are made by improving the standard of society health. The 
Ministry of National Developmental Plan has therefore set a target indicator, which aims to reduce the number of MMR from 359 per 100,000 live births to 306 per 100,000 live births and IMR from 32 per 1,000 live births to 24 per 1000 live birth as well (Ministry of Health Indonesia, 2015).

MMR and IMR can be decreased if the number of high-risk pregnant women reduced. In 2010, 34\% of women were classified into high-risk pregnancy. According to the health profile data of West Sumatra in 2012, the number of high-risk pregnant women in West Sumatra reached 23,037. In Bukittinggi, 568 out of total of 2,546 pregnant women were classified into the high risk pregnancy group in December 2017. It means that at least $22 \%$ of the total pregnant women in Bukittinggi were classified to high risk of pregnancy. The data shows that the number of highest risk pregnant women in the working area of Rasimah Ahmad Health Center was 84 (Bukittinggi Health Office, 2017).

To anticipate this, an approach should be made through the individuals who are closest to the community to provide information about high-risk pregnancies. Health cadres are among the closest ones who get training from the Ministry of Health to increase knowledge in order to decrease the number of MMR and IMR. One of the spesific roles of health cadres is to assist pregnant women. In general, the activity is aimed to detect and recognize the three too late actions to the pregnant women, namely providing motivation and counseling to them, their family and other people to help those to gain birth-giving services by health workers. Cadres have been prepared in terms of knowledge and attitudes in early detection of high-risk pregnancy (Sidoarjo District Health Agency, 2014).

However, cadres' knowledge and attitudes regarding their roles and duties as an assistant for high-risk pregnant women and early detection of high risk are still very low. Therefore, it is necessary to increase the knowledge and attitude of health cadres or volunteers in terms of early detection of high-risk pregnant women by using appropriate and effective learning media sources in accordance with the conditions of knowledge and needs of cadres in the city of Bukittinggi. The purpose of this study is to explore and identify the perspective and experience of health cadres in providing assistance to high-risk pregnant women.

\section{Research Method and Material}

This research uses a qualitative study. It was conducted at the working area of Rasimah Ahmad Bukittinggi Health Center in July- October 2018. The subject of this study consisted of health professionals, maternal and child health program holder, policy makers or the head of the health center. The data were collected by In Depth Interview and Focus Group Discussion. The validity of the data was calculated by using triangulation technique. The data were analyzed using interactive analysis.

\section{Result and Discussion}

\subsection{Perspective Exploration and Experience of Health Cadres}

Implementation of Early Detecting High Risk Pregnancy at the Health Center

Health cadres are the closest individuals to the community who have received training from the Ministry of Health to increase knowledge and reduce MMR and IMR overall. This is the result of the interview with cadres:

"The health center program is said to be good if there is a high risk, we will immediately go to pregnant woman's house”. (Informan 1.1)

"If there is a high risk pregnant woman in our area, we will go and see her. Then we will report her condition to the health center. After that, health officer will come to her the house. So, we cooperate with the health center. It's been handled well." (Informan 1.7)

Cadres neither fully understand about high-risk pregnancy, and nor aware of the early detection of high-risk pregnancies, even though they have been given the training by the health center, but there is no handbook for cadres in providing information and counseling to mothers other than KIA book as stated by the following cadre:

“We only use KIA books most of the time”. (Informan 1.1)

"Sometimes we also give counseling based on experience" (Informan 1.5)

This is the result of interview with informan 2 that the achievement program is still far from the target.

"The achievement is still below the target. It should be 58 while the achievement is 49.4. Based on the data, we were not maximal in implementing the early detection program. This is due to the community which has not been fully monitored by the officers because of the limited the number of officers. In the meantime, cadre doesn't meet society's needs. Moreover, the mobility of population is quite high. Last but not least, it is caused by the cadre who doesn't report the cases or they are late in reporting them. (Informan 2) 
The implementation of high-risk early detection at the health center is by providing counseling at cross-sector meetings, providing insight understanding to cadres. Later, the cadres will pass through the information to the community. The following is the quotation from the interview:

"Actually, the implementation should be crossline. But there are several obstacles across the sector. One of them is dealing with people's assumption which mentions that people's health is the responsibility of health cadres themselves. This may occur in the other sectors. The activities held in the health centre are usually conducted with the cadres. But we also want to collaborate well with other community sectors, such as neighboring community, people's community or community leaders. We try to give some general information, not to say the specific ones, unless to the specific classes. We also convey information via cadres and they send them to the community." Iinforman 3)

\section{Role of Health Cadres}

Health cadres are those who are originated from the community chosen by the community themselves and work voluntarily to become organizers in Desa Siaga. The roles of cadre have been assigned before since they are not professionals and have limited knowledge. Cadres at the Rasimah Ahmad Health Center conveyed the roles they had performed as the following interview excerpt:

"The role of the first cadres is to provide the counseling to pregnant women together with the health center staffs. They suggest them to come every month to the posyandu to measure their weight and head diameter. They educate the women to keep their pregnancy. They are also given vitamins including blood vitamin supplement by the the health center. "(Informan 1.4)

The result of the interview with informan 2 found that the cadre's role was still not optima yet. The following is the excerpt of the interview:

"The role of cadres in this program is that, they play a role, but it is less optimal. This happens because the cadre has a double duty. They have to balance between their work and other activities as well. So, if cadres have shared their thoughts on this program, they are certainly not optimal anymore. To conclude, the cadre's role is still far from expectation". (Informan 2)

The statement above is also supported by informan 3 who said that cadres have done their role but it is not satisfactory yet. The following is the excerpt of the interview:

"Ideally, the cadres have to collaborate well with the midwives in health center who hold the program related to this. The cadres did their roles, but it seemed unsatisfied. They have to be assigned to do their job in order we can get the results. It may be perfect and maximum, but at least we try to get close to the target, for example the target is ten, we can, at least, get eight or seven which is more intensive." (Informan 3)

Obstacles in the Involvement of Health Cadres in a High-Risk Pregnancy of Early Detection Program.

Cadres said that they have tried to carry out their duties, but sometimes the community is not cooperative in implementing the program as stated by the following informan:

"I ask a high risky pregnant woman to go to the posyandu but she doesn't want to. Whenever I ask her to do conseling, she doesn't want to participate either". (Informan 1.7)

The statement of informan 1.7 was also supported by informan 1.6 who stated that the community, especially pregnant women, did not want to cooperate.

"There is a pregnant woman who does not want to check their condition to the midwife in health center. She only wants to go to a private practical midwife. If I told her to go to the health center, she will refuse. Even though we asked her to have a pregnancy check, she is reluctant to do so with the reason that she had already been consulted by another midwife." (Informan 1.6)

The result of interview with informan 2 said that: "the involvement of cadres in high risk pregnancy programs is quite influential because the cadres here are hands-on from the health center. But as we discussed earlier, cadres have different background knowledge, different education, social and economics. So their understanding is also different. But we think that some cadres have already reported the high risk pregnancy women too late even there are also those who do not know what they want to report. That is why the importance of knowledge and understanding of cadres play an important role. On the other side, cadres also have other activities outside of their duties as alert women, so they also have to share their tasks with others". (Informan 2)

The above statement is supported by informan 3 as the following interview excerpt:

"As I told before, sometimes even if the program is not well impemented in general, it does not mean that all cadres 
are not capable. Although most of them did that. Its our task to remind the cadres. Since it is an empowering program because we empower people to be independent, we expect it to give good result, for example in sticking P4K sticker. It should be given at the beginning of the program. Actually it should be posted soon, but sometimes we still need to remind the cadres again." (Informan 3)

\subsection{Identification of Module Preparation in High Risky Early Detection}

The Causing Factors of High Risky Rates of Pregnancy

A risky pregnancy is a pregnancy that will cause high danger and complications, both to the mother and to the fetus she conceived during pregnancy as compared to normal pregnancy and childbirth. Based on the information obtained from interview with informan 1.5, lack of knowledge of the pregnant women is claimed as the major factor that cause high risk pregnancy as it is stated below:

"There is a lack of knowledge of the pregnant woman themselves. They may not understand about $4 T$ which is too young, too old, too close and too far. Sometimes they don't know their proper age for each program, such as the age to get pregnant or to use contraception. Sometimes the community think contraception is to prohibit them of havin children. So it's all about their knowledge." (Informan 1.5)

The result of the interview with informan 2 states that the factors that cause high rates of risky pregnancy are lack of knowledge and awareness of the community.

"The high risk pregnancy rate in our health center occurs because of the lack of knowledge of the community. They do not understand about $4 T$ and 3T, so they consider that it is normal to get pregnant too old or too young. They are not aware of the problems they have during pregnancy either. For example, they consider that dizziness or low HB index as normal. They also think that small amount of bleeding occurs just because they are too busy or others. Besides, the lack of understanding still exist. We have given them some knowledge but because of their different educational background, they also have different understanding one another. If health center trains five cadres, only one or two of them will understand. Sometimes cadres have already discovered the high risk pregnant women, but sometimes the pregnancy is already at 7 months gestational age. So, it's too late for us to anticipate. Next, the problem is about the lack of information facilities. Luckily, we have overcomed this problem by using printed leaflet and banner installation. In fact, we need information media in the form of audio, video, sound recording, advertisement, film, etc." (Informan 2)

The statement is also supported by the result of the interview conducted with informan 3 that the causing factors of high rate of risky pregnancy is lack of knowledge and awareness of the community. The following is the quotation from the interview:

"As a whole, the problem might lay on the knowledge. Health workers might have already provided information in such a comprehensive manner but because of several things, the information changes. There are a lot of media nowadays. So they must possess knowledge even a bit, because there are a lot of media including social media nowadays. But the problem may be resulted from the lack of awareness that makes them think it is still acceptable to get pregnant at certain age and so on." (Informan 3)

Efforts or Policies to Overcome High Risk Pregnancy

Several efforts have been made to reduce high risk pregnancy. Those are conducting counseling, training cadres, and forming cadres of maternal alert friends as the following interview excerpt:

"Some efforts to reduce high risk pregnancy have been done. Health center has disseminated about 4T and 3T to the public in counseling of childbearing age couples. It has also informed cadres in meetings of posyandu or poskeskel cadres in improving knowledge about high-risk pregnancy. The health center has also made several leaflets about the danger of high-risk pregnancy. It has formed partnership program called 'Teman Siaga Ibu'. The task of these cadres is to make it easier for the cadres to gather all pregnant women, especially the high-risky ones, to record and to report all pregnancy problems". (Informan 2)

Handling high-risk pregnancy rates could be reached by increasing knowledge or disseminating information to pregnant women about the high risk both through a regular class of pregnant women and other health services such as Posyandu as stated by informan 3:

"Basically, some of us go directly working with cadres and others but we also hold a meeting. So, we have special classes like pregnant women classes. As a matter of fact, not all invited persons attend the class. People can get more information at that place. We can detect the pregnancy later to see whether they belong to high risky ones. Few pay less attention to that. It is hoped that the information given will be able to reach all of those who might have been pregnant. Hopefully, they start being aware of the matter."(Informan 3) 
Empowering Collaboration between Midwives and Health Cadres in the Implementation of Early Detection of High-Risk Pregnancy.

Efforts have been done by health centers to enable collaboration between midwives and health workers by giving them enough knowledge and early techniques to categorize pregnant women into high-risk pregnancy. This is in accordance with the following interview excerpt:

"When it was time to go to the field and no cadres with us, we have tried to give some insights to the cadres. They have been acknowledged with several techniques and the way to detect pregnant women who are categorized into high .risk ones. We have been trying to empower our cadres to do so. We assume that there is no health worker, yet they still can do their job even well". (Informan 3)

\section{Discussion}

\subsection{Perspective Exploration and Health Cadres' Experiences}

Implementation of Early Detection of High Risk Pregnancy at the Public Health Center

The result shows that the implementation of early detection of high-risk pregnancy at the health center was by providing counseling at cross-sector meetings, providing understanding to cadres and conveying information to the community later.

Introduction of the high risk pregnancy is done through active screening or detection of risk factors to all pregnant women as early as possible in early pregnancy by both trained health or non-health workers in the community, for example $P K K$ organization, Karang Taruna cadres, pregnant women themselves, husband or family. Antenatal screening activity, through home visit, is the first step in maintaining their health. It involves into one of the anticipatory actions to prevent maternal death. The first screening is to group pregnant women into risk or no risk ones. High risk pregnant women with risky factors can be observed and found as early as possible in the early period of pregnancy to the pregnant women who are healthy and feeling healthy.

The research conducted by Widiastuti et al. regarding Early Detection Management of High-Risk Pregnant Women in Antenatal Services at Jepara District Health Center Level found that the low coverage of health center had a low ratio of midwives per population. SOP had not been posted yet. Furthermore, the plan was carried out per year and the training was conducted every six months. Feedback from the supervision was delivered orally. High coverage health centers also have a low ratio of midwives per population. Planning is carried out per month through mini workshops. Monthly guidance is also provided. Supervision feedback is delivered in writing. There are some consequences if the report is delivered too late.

Roles of Cadre

The result shows that the role of cadres was still not satisfied in carrying out early detection of high risk pregnancy. The lack of knowledge of these cadres regarding risky pregnancies and lack of cadre efforts in carrying out high-risk early detection of pregnancy were taken into account. Cadres began to work if they had been instructed by the health center staffs.

Cadres are community workers who are considered as the closest individual to the community. The health department makes a policy regarding training for cadres intended to increase knowledge, reduce maternal and child mortality. Cadres are responsible to the local community and leaders who are appointed by health service centers. It is expected that they will be able to carry out the instruction given by the supervisors in the team work of a health team.

Cadres require media for training and development in order to do their tasks. A research conducted by Khomsah entitled "Factors Related to the Participation of Posyandu Cadres in Detecting Risk Factors of Pregnant Women in the Working Area of Buayan Health Center Kebumen Jawa Tengah", shows that cadres who were knowledgeable about antenatal detection, high education, reward, positive attitude, high motivation, supervision, and get support from PKK to participate more in the detection of antenatal risk factors. Meanwhile, while age and training in this study were not related to the participation of cadres with risk detection of pregnant women. (Khomsah 2012)

The activity of the cadres' role in detecting risk factors for pregnant women is to recognize, discover, record the identity of pregnant women with high risk factors, report, recommend regular pregnancy checks, recommend maternity with health workers and suggest continuation treatment.

Obstacles in the Involvement of Health Cadres in a High-Risk of Early Detection Program of Pregnancy

The result of interview with informan concludes that the barriers of the cadres' involvement in the early detection of high-risk pregnancy programs due to the lack of cadres' dependency in carrying out their tasks as posting P4K 
sticker. Cadres should explain it to the pregnant woman since the beginning of the pregnance. In fact, cadres still cannot do it themselves and are still reminded by health workers at the Health Center. This might happen because cadres have so different background, knowledge, education, social, different economic background that they have different understanding. In the meantime, cadres also have other activities besides their duties as pregnant women's friend so that they have to share tasks and thoughts.

The role of health cadres in Posyandu cannot be separated from health services, especially maternal and child health services. The role of cadres is collaborated with the role of midwives and other health workers. The role of cadres in Posyandu is to give counseling to TOGA, TOMA and traditional healers, collecting data of pregnant women, assisting midwives in conducting PWS KIA Besides, they have to collect data of pregnant women, measure them, install $\mathrm{P} 4 \mathrm{~K}$ stickers, give $\mathrm{MCH}$ books to pregnant women, record KIA and report activities, referring pregnant women who need special treatment as complication, and others.

\subsection{Identification of Module Preparation in High Risk Early Detection of Pregnancy}

\section{The Causing Factors of High Rates of Pregnancy with Risk}

The result of interviews with informen concludes that the causing factors of high rate of pregnancy due to the lack of community knowledge about pregnancy with risk. It is also affected by the lack of public awareness of the complications in high-risk pregnancy. Another thing is the lack of knowledge of cadres in providing counseling in the community and lack of mass media in the form of audio, film or video. Therefore, the community, especially the mothers, do not understand about the danger threatens their life if they are pregnant or giving birth too young or too old. They also have to deal with the risks they have if they give birth too often, or have too many children.

One of the ways that have been run by the health center program is giving counseling to cadres and cadres convey it to pregnant women. Mostly, it is done by telling narrative or based on experience only. It is difficult to recall since it just involves one sense, namely hearing sense. This counseling should be done by the help of health promotion media so that the information is received optimally (Harlen Yunita, Tjahyono Kuntjoro, 2013).

\section{Efforts or Policies to Overcome High Risk Pregnancy}

The result of interview with informen shows that the health center has made various efforts to overcome high-risk pregnancies, such as conducting counseling to couples of childbearing age, training cadres to increase knowledge about high-risk pregnancy as well as distributing leaflets to pregnant women.

Theoritically, some efforts to cope with the high number of risk pregnancy can be done by increasing knowledge or disseminating information to the pregnant women regarding high risk pregnancy, both through special classes for pregnant women, media-based counseling, as well as other health services such as posyandu and medical examining of pregnant women's health.

Coaching is one of the ways to increase motivation of cadres in running early detection of high-risk pregnancy program optimally. The motivation is mostly to give encouragement to someone in order to cooperate optimally to reach the planning. The well-done coaching will produce beneficial and useful cadres.

The follow-up sosialization if high-risk pregnant women is found, cadres should be the closest person who are capable to inform all related information and defend good mutual relationship. Cadres should approach the community. They should be well-known and realiable so that they can function optimally in giving counseling to pregnant women. Furthermore, high-risk pregnant women can pass their pregnancy period well and deliver the healthy baby.

Empowering Collaboration between Midwives and Health Cadres in the Implementation of Early Detection of High-Risk Pregnancy

The result of the study concludes that the efforts that have been made by health center in empowering cooperation between midwives and health cadres, are by being equipped with knowledge, and the initial techniques in categorizing high-risk pregnant women. Health center are expected to provide counseling to cadres on a regular basis, so the latest knowledge or information in the field of health in the community, especially high-risk early detection of pregnancy can be given to cadres.

The roles of cadres in health problems are to see, hear, record to find symptoms and health problems, report and make simple prevention and handling efforts. These were obtained by cadres from counseling and training conducted by Puskesmas or health workers.

In carrying out and finding symptoms, signs and problems in the community including the high risk of pregnancy, obtaining information from cadres of the Posyandu, community reports, home visit and community social 
activities are needed. Hence, it is expected that cadres can suggest to give medical treatment to the Puskesmas if they find problems especially high risk pregnant women.

The role of cadres in the case of pregnant women with high risk pregnancy factors is to be able to recognize risk factors, explain to mothers and their family to carry out routine pregnancy checks to the health center or to health workers and refer pregnant women with high-risk pregnancies.

Iswarawanti states that cadres are expected to be able to link between officers or health experts with the community and help communities identify and deal with their own health needs. Cadres are also expected to be able to provide information to health officials or health professionals who may not be able to reach the community directly, and be able to encourage health workers in the health system or at the health center to understand and respond to community needs. Cadres can help mobilize community resources, advocate for the community and build local capacity.

\section{Conclusion and Recomendation}

\subsection{Conclusion}

Health cadres still do not fully understand about high-risk pregnancies. They do not know yet the efforts made in early detection of high-risk pregnancies, and the lack of experience of cadres in early detection of high-risk pregnancies so that early detection of high risks pregnancy has not run well. It is affected by the lack of instructional resources for the cadres through media in providing information /and ounseling to pregnant women other than KIA books. In order to increase cadres' knowledge, especially regarding to the high-risk early detection of pregnancy, learning media is needed which can be used by health cadres as a reference in providing quality assistance.

\subsection{Suggestion}

The head of the public health center needs to make a policy to initiate some trainings, incentives, awards, and so on. Maternal and child program coordinators are expected to make a guideline for cadres, and schedule for regular meetings with the cadres. Cadres need to be aware that early detection of high-risk pregnancy is necessary to reduce MMR and IMR.

\section{Competing Interests Statement}

The authors declare that there are no competing or potential conflicts of interest.

\section{References}

Agustina, I. (2017). Module Teaching Materials. Http: // www. irnien.files.wordpress.com

Al Rahmad, A. H. (2015). Effectiveness of Training on the Use of KMS Companion Modules on Increasing Knowledge and Accuracy of Cadres in Interpreting Toddler weighing results at Posyandu. Journal of Nasuwakes Scientific Health, 8(1).

Andy, P. (2013). Development of Thematic Teaching Materials - Complete Applicative Guidelines. Yogyakarta: DIVA Press.

Astuti, Dwi Puji Tiarah , et al. (2016). The Level of Knowledge and Antenatal Care Behavior of Pregnant Women Against Pregnancy with Risk in the Work Area of the State Health Center I of Jembrana Regency. Retrieved from http://www.ojs.unud.ac.id

Budiman et al. (2013). Capita Selekta Knowledge and Attitude Questionnaire in Health Research. Jakarta: Salemba Medika.

Bukittinggi City Health Office. (2017). Bukittinggi City Health Profile. Bukittinggi: Ministry of Health of the Republic of Indonesia.

West Sumatra Provincial Health Office. (2017). Profile of West Sumatra Health Office in 2017.

Sidoarjo Health Office. (2014). Posyandu Cadres Strengthen Bumil Risti Assistance Program.

Endriyani, A. et al. (2017). Analysis of Cervical Cancer Screening Program in Sleman, Yogyakarta. Retrieved from http://www.ejournal.unisayogya.ac.id

Fallen, R., \& Budi Dwi, K. R. (2010). Lecture Notes for Community Nursing. Yogyakarta: Nuha Medika.

Republic of Indonesia Ministry of Health. (2015). Ministry of Health Strategic Plan for 2015-2019.

Khomsah, N. (2012). Factors related to the Participation of Posyandu Cadres in Detecting the Risk Factors of Pregnant Women in the Work Area of the Puskesmas Buayan Kebumen Jawa Tengan. Retrieved from 
http://www.lib.ui.ac.id

Kusmiyati. (2011). Prevention of High Risk Pregnancy. Bandung: Cv Candra.

Manuaba. (2007). Introduction to the Manuaba Obstetrics Lecture.

Muslihatun, W. (2010). Neonatal, Infant and Toddler Childbirth Care. Yogyakarta: Fitramaya.

Notoadmojo, S. (2010). Introduction to Health Education and Health Behavior. Yogyakarta: Andi Offset.

Notoadmojo, S. (2007). Public Health Sciences and Arts (Revised Ed.). Jakarta: Rineka Cipta.

Riyanto, A. (2011). Application of Health Research Methodology. Yogyakarta: Mutia Medika

Rochyati, P. (2003). Antenatal Screening for Pregnant Women. Safe Motherhood-Lab / SMF Obgyn Center at Dr.Sutomo Hospital / Surabaya UNAIR Medical Faculty.

Wawan, et al. (2011). Theory and Measurement of Knowledge, Attitudes and Human Behavior. Yogyakarta: Mutia Medika.

Widiastuti, T., et al. (n.d.). Early Detection Management of High-Risk Pregnant Women in Antenatal Services at the Jepara District Health Center Level. Retrieved from http://www.media.neliti.com

World Health Organization. (2017). World Health Statistics.

World Health Organization. (2015). The 2015 World Population Prospect.

World Health Organization. (2014). 2014 Maternal Mortality Report. Switzerland: United Nation.

\section{Copyrights}

Copyright for this article is retained by the author(s), with first publication rights granted to the journal.

This is an open-access article distributed under the terms and conditions of the Creative Commons Attribution license (http://creativecommons.org/licenses/by/4.0/). 